\title{
Options and problems in environmental management and evaluation
}

\author{
J. R. Lewis \\ Wellcome Marine Laboratory, University of Leeds, Robin Hood's Bay; \\ N. Yorkshire, England
}

\begin{abstract}
Although logical compromise agreement between all the conflicting users of the sea seems the most obvious way to protect marine life, we have in practice mainly ad-hoc restrictions aimed at protecting habitats or species, or at trying to prevent chemical/physical deterioration of the environment. The establishment of reserves on biological rather than touristic grounds necessitates consideration of the criteria, appropriate to marine life, that should be used. Successful reserve management or species protection measures depend upon distinguishing between natural and man-made changes, an ability that can be enhanced in part by appropriate disturbance experiments. Anti-pollution measures have centred upon effluent input rather than biological effect in the field, with "acceptable discharge levels" being based upon lethal and sub-lethal experimental effects. But the ultimate criteria of environmental well-being are ecological responses at the population and community levels where, unfortunately, many natural and man-made influences produce similar changes. Knowledge of community dynamics and a resuiting ability to discount natural events require long-term studies and are slow to accumulate. Thus while short-term sublethal studies proliferate many ecological data remain uninterpretable except in localities of gross and obviotus pollution (including tanker accidents). The scarcity of sub-lethal and ecological effects in the field is even supplemented by ecological changes that are contrary to expectations based on pollution loadings. Is this because ecological expertise is still inadequate, or because experimental and environmental loading data grossly overstate the risks and are largely irrelevant at the community level? Can we assume that fears of chronic pollution are unfounded or must we intensify our efforts? If the latter, in which direction?
\end{abstract}

\section{INTRODUCTION}

At one time we had "Conservation", which in essence is somewhat negative, retaining what there is. Now we have "Management" with its implication of positive planning and forward looking. Whether there is a real difference or not it is necessary, if we accept that our objective is "the maintenance of natural conditions and ecological diversity", to (a) recognise the threats and assess their relative importance; (b) devise ways of countering or minimising the effects of these threats; (c) acquire sufficient understanding of the natural situation to be able to judge the efficiency of the countermeasures.

A moment's consideration indicates the scale and complexity of the subject. Virtually every activity of man which impinges upon the seas is antagonistic to the declared objective. Even those that depend upon the continuance of natural marine resources, such as fishing or biological education, are threats to greater or lesser extents, while the 
wider range of uses can provoke economic/political/social conflicts in which the different self-interests can often advance equally convincing justifications.

Not the least of our problems as biologists is that which is met so often in environmental debates, of trying to persuade society to balance largely immeasurable attributes against hard economic facts or predictions. But even if all the issues could be made tangible and quantified in some way could we expect a balanced judgement, acceptable to all, as the outcome? The idea of rational schemes of zoned usage of the sea is very attractive. Surely thinking men coming together to resolve ever-increasing demands must see that agreed compromise is the only way? But could we, even among ourselves, agree for example on how much physical and biological damage by bottom trawling is compatible with maintaining natural conditions?

If I sound cynical it is because I am. If we have so much difficulty in persuading those whose living depends upon the sea (together with their governments) to agree on measures to ensure the continuation of exploitable fish or whale stocks, how much hope is there when we seek to balance the less tangible conservation values against economic/social pressures? There have been conservation successes in most countries, but in general I suspect that biological matters will carry weight mostly when there is not a strong economic conflict, or when they coincide with some other over-riding, but coincidentally beneficial, requirement. Thus it is primarily the aesthetic or health aspects of sewage pollution, and the commercial impact upon tourism rather than biological considerations that lead to action. It will be the need to conserve oil or to avoid swingeing insurance and compensation claims that will reduce oil pollution, not a desire to protect nature. If and when "national plans" exist, I suspect that they will largely consist of a series of un-coordinated responses to local economic needs or opportunities with little in the way of an overall view. The most severe threat to coastal wildlife, the piecemeal physical destruction of estuarine habitats with scant regard to their rarity or distribution, is such a case.

Whether my pessimism is justified or not I suggest that it is pointless for us to try to get involved here in the political/economic/social aspects of management in its broadest sense. Rather I see a more modest but urgent need for us to ensure that our scientific house is in order, that we try to reach conclusions about what is happening and where the uncertainties lie, as an honest factual contribution towards the political decision making.

The best way to maintain natural conditions and ecological diversity would be to leave nature severely alone. This apparently obvious statement is made because the sea differs somewhat from the land. On the latter most communities are dominated, ecologically, by long-lived vegetation with slow, natural change-rates, and the natural progression over many years to climax conditions may involve considerable loss of intermediate physical and biological stages. Hence, even in areas rescued from man, positive measures such as felling, grazing, dredging and so on are indispensible tools in the maintenance of terrestrial and freshwater diversity when the undeveloped area in which to do so is very limited.

Marine communities, by contrast, generally lack such dominating vegetation, and the shorter life-spans and interactive processes between fauna and flora and habitat can impart a cyclical dynamism with much shorter time-scales. So although some positive manipulation by way of creating additional habitat types on a small scale is possible, our 
principal tools need only be, and indeed are, restrictions on human activity. Thus apart from the regulation of the various types of harvesting our measures are: (a) the selective protection of areas, habitats and non-commercial species from the more obvious physical misuses and human pressures, and (b) the more generalised attempts to maintain the quality of the aquatic environment overall. The former is the more restricted in scope and raises the fewest scientific problems so it is considered first.

\section{SELECTIVE PROTECTION}

Protection of localities and habitats is the basic and most obvious biological component of "management" in its broadest sense. It is particularly directed against physical destruction of habitats on an industrial (reclamation, extraction) or personal (digging, trampling) scale, and against the collecting of specimens with scarcity or attractive value. It cannot guarantee protection from water or airborne pollution although judicious placement may greatly minimise some of these threats.

"Reserves", "preserves", "refuges", "parks", and so on with various restrictions of access or usage have been set up widely in recent decades (Björklund 1974). For obvious practical reasons they centre upon coastal areas, with benthic life and the demersal fauna as the primary targets and the overlying pelagial biota as an incidental beneficiary. Protection has been afforded for many reasons : to enhance tourist appeal especially for non-hunting scuba divers; to protect breeding sites of commercial species; to roundoff a terrestrial reserve; to save a last sector of coastline against further development, and so on. All these are valid reasons and one can quickly add further scientific, educational, amenity and ethical justifications. These essentially ad-hoc defensive measures may be all that economic and other pressures will permit, but if we believe that the grounds for establishing reserves a $\mathrm{e}$ valid and that the case should be vigorously pursued I suggest that a more rational basis for the selection of reserves is required.

Later speakers will I trust explore this theme in detail but I suggest that the basic requirement of a habitat conservation programme is not the usual emphasis upon the very rich locality or the rare species but upon a representative range of a country's marine habitats and communities. No-one can anticipate the habitat or the species that will be of "value" for particular scientific, educational, aesthetic or commercial purpose in future decades, so would it not be more logical to aim for a range which, based upon a sound knowledge and realistic classification, would cover the rare and the common, the high diversity and the low, the fragile and the robust?

If this is accepted a classification becomes the first requirement. Although our knowledge is not fully adequate for this purpose, the task is far from limitless if we take into account a few characteristics of benthic communities. These are: (a) The higher frequency, compared with land, of communities dominated by a range of sedentary faunas. (b) The temporal variability within many of these communities as a result of frequent or irregular changes in physical conditions, or of the competitive and trophic interactions among comparatively short-lived species. (c) The widespread occurrence among coastal species of mobile larval stages or spores which are thus able to colonise vacant space that arises at often considerable distances from the parent population.

Community ecologists may still indulge themselves in an intricate societal classification of their species assemblages, but from a conservational standpoint any classifica- 
tion must necessarily be somewhat imprecise and flexible if it is to accord with the practical consequences of the above features. Within certain broad habitat divisions, based upon substratum and water movement characteristics, there must be sufficient flexibility to include much additional variation in space and time. While some sharply delimited physical habitats would be recognised in a classification, and some distinctive, stable communities do exist, the dynamic nature of many others precludes both the possibility of, and the need for, fine-scale classification and mapping. From this inability to deal in anything but broad terms the useful implication follows (highly distinctive physical habitats apart) that most representative reserves should be of large size, comprising multiple examples of the broad habitat type in question. This will ensure (a) that locally induced changes will not affect all examples equally; (b) a high degree of reproductive self-sufficiency in the species with planktonic stages, and (c) the existence of an adequate protecting edge - or buffer-zone.

Where broadly defined habitat/community types recur frequently along the coasts of a country there would be scope (ideally) for replication in order to include the geographically varying detail of species composition, and perhaps also to ensure a regional series of examples for possible later educational and scientific purposes.

As we turn from selection to implementation, legal and administrative matters will arise: ownership of shore-line and seabed; traditional users' rights; type of access and use restrictions, etc., etc. But to me the major problem returns us to my earlier comments about planning and conflicts, for the simple reason that where the need for reserves is greatest (i. e. on short coastlines with high urban/industrial use) the opportunities are least. Putting this the reverse way, and as I see it in the U. K., the finest examples of many types of shoreline communities are so far from any direct, foreseeable threats that no conservation action seems justified.

Since such areas support communities in what are probably (in this pollution age) their most "natural" states they could be regarded as the ideal areas for typical reserves. But if the case is made for such typical examples on grounds of "conserving part of our national, natural heritage" (the emotive grounds most likely to succeed!) do we thereby relegate as expendable other areas closer to high populations and potential naturalist users? Would this be the ultimate outcome of a broad coastal management concept trading off areas under multiple pressures for guarantees for prime localities which are not in fact at risk? Would it be better tactics from a (selfish?) biological viewpoint to forget rational planning of coastal use and just resist everything on a local basis? Or is it inevitable that while examples of all types of habitat could be retained, the number of examples of each type must decline?

The other restrictive approach is directed to species and to me this topic presents contradictions. On the one hand I know of no fish, invertebrate or alga that has become extinct because of selective collection or other activity. And recalling the high recuperative efficiency of species with planktonic larvae it is difficult in the case of most such species to postulate convincingly that even local extinction is possible. Yet local or shortterm scarcities do exist, especially among a limited number of large species of edible or collector value, and one can sympathise greatly with local naturalists and teachers in the afflicted areas.

Where commercial exploitation is the cause this should render species liable to fishery regulations. For the others, local prohibitions are perhaps needed, with the 
emphasis upon "local" since the pressure is probably only severe near distributional limits or where a highly distinctive type of habitat is rare. But it is perhaps salutary to recall that we, the professionals, frequently record a high percentage of species as "rare", but often can give no convincing explanation for this, so fragmentary is our knowledge of the distribution and the habitat requirements of most species. But if many species are indeed rare the best way to protect them is by preserving habitats generally, not by specific action.

Anything less than total restriction upon access or collection will raise questions about the efficiency of the measures and their enforcement. One will observe changes there is no doubt about this - and have to ask if they are natural or due to the inadequacy of the measures. Judgement can be enhanced by disturbance experiments involving the more obvious "people pressures". Re-establishment and growth rates after dredging, digging, stone-turning etc. will give some indication of what to expect and also of the level of disturbance that can be tolerated without causing permanent change. The location of reserves some distance from direct pollution sources affords some protection from this threat, but there is no way of isolating them from the effects of natural environmental changes. The latter therefore will also need to be known, but this is the major problem area of environmental management which is discussed below in the wider context of pollution.

\section{GENERAL ENVIRONMENTAL MEASURES}

While the extreme conservationist view opposes any deliberate disposals into the sea most people would accept that not all additions constitute "pollution" in any real sense. Not only may some additions be expected to promote productivity or cause changes regarded as desirable from one standpoint, but others may be buffered by the physico/chemical and biological homeostatic mechanisms that are known or suspected to exist in the sea and marine life. In the absence of any absolute definition or standard of pollution the most logical pragmatic criterion is the "biological effect", since it is selfevident that no significance attaches to a contaminant that has no effect. This is what matters to the general public, the industrialists, the legislators, our financial supporters. They ask: is there, or may there be an effect? Is it adverse, on what scale, and is it reversible? And we as biologists should turn the generalised enquiries into the specific, crucial question; is there a field effect at the population and community level?

In the early days cause and effect relationships presented no apparent difficulty. The principal waste was sewage and its effects were obvious - on estuarine fisheries and nasal sensitivities alike. With the wider range of waste products of today and the higher potential for massive shore-based or shipping accidents ecological deterioration and severe "kills" have become more common. However, since such localities or incidents are readily identifiable and the causes are often obvious or circumstantially so, they present managerial, legislative and financial problems rather than biological. But "hot spots" and accidents apart, it is also becoming disconcertingly apparent that broadscale field effects are less convincingly demonstrable than was expected.

Why this latter should be so must be considered shortly, but for the moment it is appropriate to note that, whether easily demonstrated or not, ecological effects reflect many factors and do not lend themselves to quantifications of a type that permit 
legislative standards to be set. They are the event we seek to prevent, and their persistence or otherwise tests the effectiveness of our preventive actions. It seems easier to measure and regulate pollution in terms of the input rather than the biological effect. Hence, the alternative approach to pollution with parallel pathways involving, on the one hand, the experimental determination of the relative toxicities of different substances, and on the other the accumulation and fate of such substances in organisms and in their environment.

Out of the toxicity studies came the concept of quantifiable "acceptable" or "permissible levels" that can be legally enforced. The gap between the simple laboratory toxicity test and the complex field situation was initially very wide. But short-term $\mathrm{LC}_{50}$ studies on adult organisms sufficiently robust for laboratory life have given way progressively to more realistic tests involving different life stages, to the detection of subtle sublethal effects and even to community simulation experiments. Nevertheless, the gap was, and almost certainly will remain, largely unbridgeable: additive or synergistic effects and homeostatic responses in the field are difficult to assess, let alone predict, so safety in the setting of "acceptable levels" is sought by an additional dilution factor (e. $\mathrm{g}$. $\times 100$ ). But the setting of discharge standards did not and does not end matters. Is the acceptable level to be determined and imposed without reference to the known or presumed mixing and diluting characteristics of the receiving waters? To an oceanic tidal coast equally with a tideless lagoon, for example? And just as there are some who will question the need for imposing certain standards and the cost of achieving them without firm evidence of harmful effects in the field, so others suspect the standards are not high enough to prevent anticipated chronic damage.

After two decades of ever-intensifying, pollution-related research the layman or the legislator might well expect that things ought by now to be fairly clear; that apart from the testing of new products, the adjusting of discharge levels in the light of experience, and the servicing of a "watch-dog" role, pollution should by now have become more of a matter of political and social priorities than of biological science. This is not the case: there are now more pollution scientists at work than ever and the literature is accumulating exponentially. Where are we going? Trying to take a very broad view I see some significant points, more that is confusing or irrelevant, and some impending credibility problems that could recoil on biological science unless we recognise them and take appropriate action.

If the broad sweep of establishing cause and effect relationships had proceeded in the way one naively hopes for at the outset of any investigation, the various parallel paths of study should by now have linked together to provide a convincing, interlocking picture. Ideally the toxicity and sub-lethal studies would indicate the most damaging substances, types of effects and the most sensitive organisms. Next the environmental and body loadings would indicate the centres of concern and should link with anticipated effects on individuals; and finally these latter effects, if sufficiently severe, would be reflected in population and community effects in the areas of highest loading or where particularly susceptible species occur. In my opinion things are not always working out this way.

On the toxicological side there is clearly no shortage of data with which to impress the public; indeed it will be a formidable task to compile summaries of all the contaminants, the concentrations and additional conditions, the organisms or parts 
thereof, and the effects that can be experimentally induced. From the avalanche of such data, and I do not think avalanche too strong a word, it would appear that there is no great difficulty in demonstrating what an intelligent layman would expect $-i$. e. that unnatural products (biocides especially) and a wide range of natural substances in high concentrations (sewage, oil, chemical elements) have effects upon marine life that are clearly or potentially harmful. While our layman would be out of his depth with the subtleties and significance of some of the experimental effects now being recorded, he would probably realise from some of the apparent contradictions that both organisms and experimenters are variable in time and space. Nevertheless he would surely come away from hearing of the range of biochemical, physiological, morphological and behavioural effects with an overall impression of impending marine doom, and approach the shoreline of any industrialised country with forebodings about what he might find or rather not find.

If, before doing so, he asked about pollutant levels in the environment or in organisms he might be relieved to find that in the open oceans at least the levels of heavy metals are not much, if at all, above background, and it would be encouraging to him to learn that some natural input sources of long standing appear to exist. The fact that pesticides had become world-wide in oceanic distribution would undoubtedly be salutary; but common-sense would tell him that although the trails of inert plastics and tar balls (some covered with barnacles) along oceanic shipping routes are undesirable they hardly justify the alarmist statements of bio-entertainers. On the other hand the contaminant burdens of some coastal waters and sediments and especially of their benthic invertebrates and some top-level carnivores would raise expectations of adverse biological effects - although he might be encouraged by the ability of some species to immobilize, regulate or adapt to pollutants. He would be puzzled by the fact that the high tissue loadings relate usually to living not dying individuals; and exclamations of impatience might well accompany the discovery that tables and maps of pollutant loadings or other adverse conditions frequently record the gradients expected around a point source but contribute little if anything about biological effects or responses. Yet are not the latter the ultimate objective of the exercise, he might ask.

We could of course point to investigations which have attempted to relate the two, and to link back to expectations derived from experimental studies. At the level of individual organisms, enzyme disturbance for example appears to have been associated with oil pollution (Payne, 1976), fin rot, tumours and skeletal malformations in fish variously with dumping grounds, pesticides and general contamination (Mearns \& Sherwood, 1974; McDermott \& Sherwood, 1975; Stich et al., 1976; Wellings et al., 1976), crustacean limb and gill damage with spoil grounds (Young \& Pearce, 1975), chromosomal damage in fish eggs with dumping grounds (Longwell, 1977), abnormal fish spawning and behaviour with heavy metals (Saunders \& Sprague, 1967; Anderson, 1971) and tainting and discolouration of commercial species with various contaminants.

On the other hand some of the above (deformities, lesions and tumours) appear to occur naturally or could not be related to pollutants (Kroger \& Guthrie, 1971; Young et al., 1973; Oishi et al., 1976; Stich et al., 1976) so the picture is confusing. Indeed, in view of a recently reported inability "to find any effects of metals off Southern California after extensive studies" (Bascom, 1978) the situation is contradictory. But whatever these and similar field studies reveal their total numbers are very few compared with the range of 
sub-lethal effects that have been experimentally induced and dominate the pollution literature. This must surely be something to reflect upon, and among several possible conclusions must lead to agreement with the view expressed in a recent I.C.E.S. (1978) report: ". . . much of recent research upon the physiological effects of pollutants is seen to be irrelevant to the immediate needs of environmental monitoring". Similarly Waldichuk (1979) writes "Much as the variety of data on adverse sub-lethal effects is of scientific interest, it may have little direct relevance for pollution control".

Nevertheless our lay interogator - beginning to understand matters better - may still suggest that if these so-called sub-lethal effects really do influence the general wellbeing of individuals they must ultimately reduce the competitive abilities of susceptible species vis-à-vis the less susceptible. Should this not lead to deaths, to failures to repopulate, to the complete loss of some species from affected localities, so that in time sub-lethal and lethal effects become indistinguishable? So why not forget subtle and apparently difficult-to-detect malfunctions in individuals and look for the grosser changes in the fauna and flora of an area?

At this level the contrasts would be striking. Dramatic accidents (especially involving oil) excite the greatest interest and reporting and some, but not all, have caused severe mortalities and community disruption. But accidents in the sea - like forest fires on land - can be expected to cause damage roughly in proportion to their scale and the coincidence of other chance factors, and while some scientific benefit may come from regarding them as massive "disturbance experiments" they remain just accidents, and as such are primarily managerial problems. Such instances apart, the greatest biological effects are associated, as one would expect, with areas of high urban and industrial development. In the latter it appears that sewage, its derivative sludges, and other types of organic inputs retain their original status as the most widespread and most damaging contaminants. (Examples include Beyer, 1968; O'Sullivan, 1971; Abbott et al., 1973; Buttermere, 1977; Griggs \& Johnson, 1978; Pearson \& Rosenberg, 1978; Bellan, 1979.) Exerting their effect primarily through $\mathrm{O}_{2}$ lack, and perhaps also via siltation or eutrophication, we see what are now regarded as the classical, pollution community transformations of reduced diversity and an increase of opportunistic species.

Similar biological features occur in the confined receiving waters of many urban/ industrial areas where it is difficult to specifically implicate any among the many contaminant inputs. Yet where, as in the Thames Estuary (Harrison \& Grant, 1976; Sedgwick \& Arthur, 1976), $\mathrm{O}_{2}$ levels have been restored through better sewage treatment, the resultant marked improvement in the fauna suggests strongly that the other components of some mixed effluents may be having relatively little effect. Away from the anticipated and obvious "hot-spots", stagnant lagoons and such-like, population and community effects are much more difficult to find even where sediment metal levels are high (Tietjen, 1977); while offshore no extensive adverse effects on fisheries have been unequivocably demonstrated (Goldberg, 1973; Johnston, 1977), and the cycles and fluctuations of the long running C. P. R. programme appear to reflect climatic not manmade influences (Colebrook, 1979). Indeed community changes have at times been contrary to those expected from pollutant data. No better way of illustrating this exists than to quote Professor Gerlach when lecturing about a sulphuric acid and ferrous sulphate waste and its possible relationship to accompanying biological changes over 10 years (Rachor \& Gerlach, 1978). No conclusion could be reached ... " since we cannot 
explain how the discharge of liquid waste could first of all be beneficial, then harmful after 1973 , and then beneficial again in $1975 / 76$ to certain animal species". Such difficulties led on to consideration of natural environmental variables, the whole study typifying the interpretative problems at the population and community level. We saw similar problems in the now quiescent controversy regarding the natural or man-made origins of the Acanthaster planci explosion and its consequences for coral reefs. Indeed I think it would be true to say that many ecologists are becoming increasingly cautious about ascribing community changes to pollution because recent work has revealed dynamic situations and interpretative pitfalls that were barely suspected two decades ago.

This brings us to what to me is the critical and most difficult problem for pollution studies and one which I hope we shall explore fairly deeply: the need for, and the development of, the ability to distinguish between natural and man-made changes at the population and community level. We have an ever-expanding catalogue of sub-lethal effects many of which have considerable academic interest in their own right but their significance seems to me slight (tainting etc. of commercial species apart) unless they have repercussions at these higher ecological levels. Indeed the significance of anything except a massive change in competitive or reproductive efficiency may perhaps be made manifest only within a natural community. A demonstrated reduction of $20 \%$ for example in feeding rate, or gametogenesis or the speed of escape reactions in a test organism may have a trivial effect or it may lead to a rapid population decline, depending entirely upon the types and abundance of its prey, predators and competitors in the natural situation.

This was indeed implicit, if not so expressed, in the original emphasis upon field effects. Not realised until recently were (a) the extents to which the baselines from which to measure all types of ecological change were themselves varying in many ways for natural reasons, and (b) that there is no universally applicable criterion - either quantitative or qualitative - by which to describe or measure the "health" of a community. Change is the ecological norm, and whatever statistical significance may be ascribed to any change, its biological significance in terms of environmental health is a matter of ecological judgement. This must be based upon a sound knowledge of the species and community concerned because as Perkins (1979) has recently illustrated, the potential for misinterpretation may be disconcertingly high.

The practical advantage of, and the search for, some fairly quick means of identifying a harmful change are, nevertheless, understandable. It is logical to expect that warning of impending deterioration could come from the first indications of that low diversity and abundance of a few tolerant, opportunistic species which characterise hotspots and which have been seen to develop in some long-term studies of discrete input areas (Pearson, 1975). The rapid advances in marine ecology during recent years show that this expectation may be justified, but they also warn most emphatically that the shorter the period of investigation the less reliable such measures may be, especially if not accompanied by other data on contaminant loadings, bioassays, etc. The diversity of species, we now know, varies considerably from one healthy community to another, and can change abruptly in the same locality for entirely natural reasons, both physical and biological, while opportunistic indicator species are not confined to artificially stressed areas. On the other hand, when diversity is expressed as an index, a single numerical 
value, changes in this, as in other data-crunching measures such as biomass, may appear trivial yet conceal the changes of species, of individuals and of age and size distributions which may be vital for full ecological assessment.

More recently, departure from an expected log-normal community structure curve has been proposed as an early indicator of pollution stress (Gray \& Mirza, 1979). The supportive evidence appears convincing, but if the history of diversity and indicator species is any guide, time and use will similarly circumscribe and re-define the range of communities and conditions which permit confident application. With such limitation as a possibility for any new assessment tool, uncritical initial use should be avoided always - especially by those in the "instant ecology" business.

Fundamental to the search for and use of means for assessing community change are two possibly controversial matters. Are there indeed community attributes which, if not quite universal, are sufficiently widespread and sufficiently frequent to be regarded as "natural laws"? Second, to what extent can deviation from such an attribute, expressed numerically or graphically, be interpreted accurately on the basis of that deviation alone and without understanding of the biology of the component species?

Within my own study habitat (the rocky littoral) community dynamics are well known and several ecological "universal truths" have proved to be not so. As a result I incline to the view that there is a "diversity" of successful ecological organisations and conditions which fits poorly into the classifications and configurations we try to devise. Doubting therefore that new, universally applicable indicator tools await detection the most certain way of minimising interpretative error remains as before: to expand the number of habitats and communities for which we have adequate data, and preferably understanding, about the many possible facets of natural community and population variation with time.

The reasons for the present lack of adequate ecological data need to be better known. First the known range of natural factors causing changes is steadily increasing. One looked initially to the local physical conditions and the frequency with which a particular adverse factor occurs, e. g. damaging or sediment-disturbing storms; $\mathrm{O}_{2}$ depletion by stagnation; abnormal reductions in salinity. But increasingly it appears that, within fairly broad habitat limits, the abundance of many species and therefore community structure is determined primarily by the trophic and competitive interactions between the several or many species which are all capable of living in that habitat. So the ways by which species impinge upon each other, directly or indirectly, at what stage in their life cycles, with what intensity and frequency, and with what consequences for the whole community have all become part of the essential background knowledge. Overlying these essentially localised events are the fluctuations of broadscale climatic and hydrographic conditions (Southward et al., 1975; Lewis, 1976). When severe these can cause widespread mortality especially to species near their geographical limits; when slight they may still impinge upon the interactions and reproductive rates of particular species and so impel community changes in different directions. The geographical extent of a biological event is thus a vital but often missing clue to its cause.

The second major problem is the time scale of natural events. While life cycles themselves are often seasonal and roughly predictable in time, the frequency of "good" or "poor" recruitments is highly variable, and destructive events such as storms or abnormal temperatures may occur randomly within a year or even a decade. Nor are the 
biological consequences of such events always apparent at once or short-lived, for when community composition owes much to biological interactions a change in one important species may start chain reactions that persist for many years. Clearly one cannot know the detailed biological history of any locality unless it is under continuous study. One can however acquire an awareness of the types of events, can even simulate them to some extent, and then apply this knowledge to the interpretative task.

But clearly time-scales extending into several years, possibly a decade or more, are a severe deterrent to those involved in the scientific career contest. The relative merits of " $r$ " and ' $K$ " strategies are much more clear in the academic world than elsewhere in nature. There is a premium upon being an " $r$ " type, an opportunist with a rapid productive output (though not necessarily a short-life span). As a result long-term ecology is the poorer and the garden of perennial knowledge may perhaps become a bed of annual weeds!

Both the time-scales and amplitudes of ecological change are unpredictable in advance, and when short-term studies are carried further they start to show longer term patterns not previously expected. As a brief contribution to this aspect I have previously

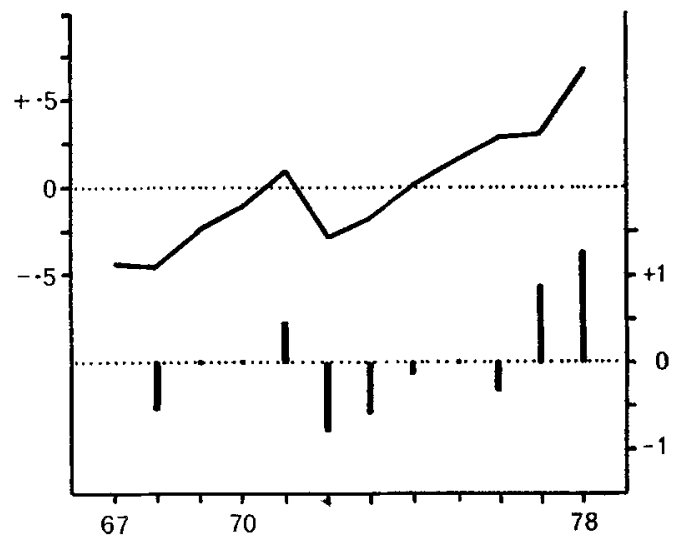

Fig. 1. Year-end density (continuous line) and annual recruitment (columns) of Patella vulgata at Robin Hood's Bay from 1967-1978. Deviations astride each 12 year mean are expressed in units of $100 \%$

shown littoral fluctuations within 5 and 10 year periods (Lewis, 1977) in which various short-term events appeared paramount. Figure 1 shows further summary data over 12 years for one of the "key" species (Patella vulgata) on sites where no local factor intervened sharply enough to disrupt the developing sequence. These data highlight the problem of arriving at mean values that have practical significance and show the sheer futility of rapidly determined "base-lines". The present densities (still rising and now > $1000 / \mathrm{m}^{2}$ ) are well above anything I have known or even expected, and they will surely fall again some time. One can readily imagine the concern, the cries of "pollution", if these observations had begun, not at the start of what proved to be an increasing phase, but at the start of a decline of similar proportions and for which no natural cause was known. In the event, as Figure 1 demonstrates, density in this species is related to recruitment rate, but this fact only leads on to questions about the control of recruitment. 
I have argued elsewhere (Lewis, 1976) and now simply repeat my conviction that recruitment, especially in communities with a "key-species" organisation, deserves priority study because this phase is often most sensitive to both natural variables and to pollutants, and because the ability to re-populate is the ultimate criterion of biological health and well-being.

Table 1. Considerations regarding environmental evaluation

Experimentally-induced effects strongly suggest that there will be adverse field effects

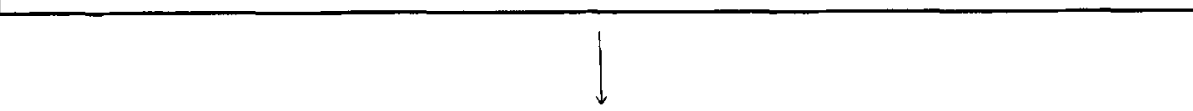

But ecological impacts are difficult to identify because natural variability is much greater than expected

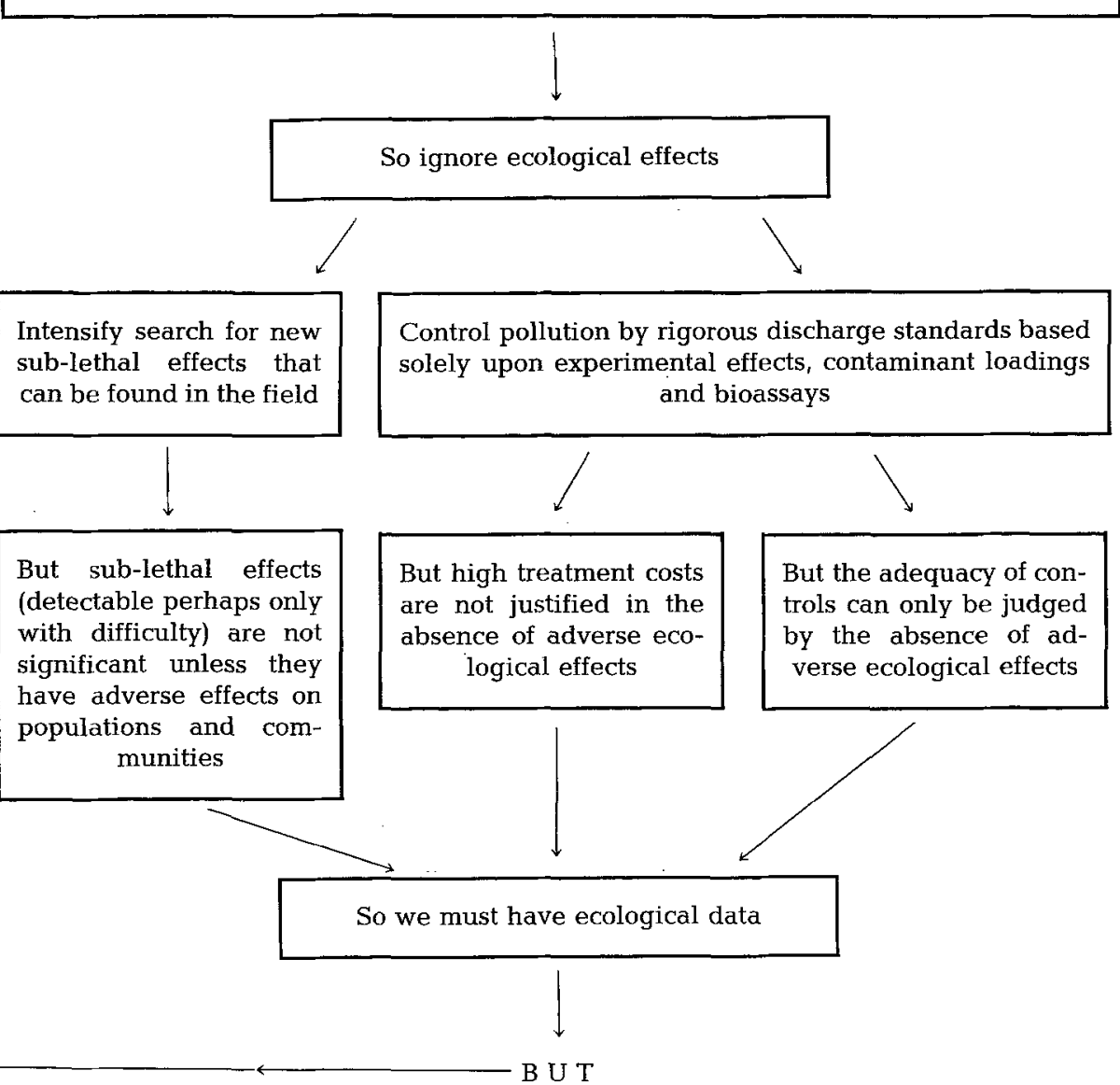




\section{CONCLUSION}

The major threats are habitat destruction, persistent gross pollution and overexploitation; their effects are obvious even to the public and occur where expected; and the remedies are dependent upon social and economic priorities. While there are undoubtedly many aspects of scientific interest to learn from a grossly polluted situation, they contribute little extra to the stated fundamental objective of maintaining natural conditions and diversity.

The more subtle threats of chronic pollution well away from the hot-spots, and which because of their subtlety have always been seen as potentially the most dangerous, do not appear to have developed and produced effects on the scale that was feared a decade ago. As a result the situation leads to circular discussions which may run roughly as shown in Table 1.

The almost instinctive scientific response to such uncertainty would be to ask for more resources, to get more experimental and ecological data, to develop new techniques for the detection of effects of all types at all levels. Certainly between the two extremes of laboratory effects and community ecology there appears scope for more effort for this is where, so to speak, the expected effect seems to be lost. Would more understanding of pollutant pathways, immobilisation, degradation and the like resolve matters? Should there be more cooperative work linking effects studies, contaminant loadings, bio-assays and ecology? Would it not help, for example, if effects and accumulation work ignored good accumulator species of high tolerance, and concentrated upon those species which have a key ecological role in particular communities, for if these succumb the community consequences could be considerable. At this final community level one outstanding priority exists. The greatest source of interpretative error is to assume much greater stability than exists. Accepting that data without understanding are unsatisfactory it would at least clarify interpretation and future research planning simply to know whether stable, equilibrium communities are frequent or rare in coastal benthos.

Many and various other research priorities will doubtless be proposed, but finally we come to the basic matter that society will raise sooner or later. If after all the recent, intensive effort there is still difficulty in finding chronic effects upon communities does this not suggest that such effects are negligible? That while the initial concern over chronic effects was justified is it not now time to acknowledge that it is only acute pollution that matters?

If we answer negatively and argue convincingly about timescales or the need to "play safe" until we know for certain (will we ever?) we must also demonstrate, even more convincingly, that future research will be in the most relevant areas.

\section{LITERATURE CITED}

Abbott, B. C., Soule, D. F., Oguri, M. \& Soule, J. D., 1973. In situ studies of the interface of natural and man-made systems in a metropolitan harbor. - Helgoländer wiss. Meeresunters. 24, 455-464.

Anderson, J. M., 1971. Assessment of effects of pollutants on physiology and behaviour. - Proc. R. Soc. (B) $177,307-320$.

Bascom, W., 1978. Mediterranean clean-up. - Mar. Pollut. Bull. 9, 196. 
Bellan, G. L., 1979. An attempted pollution abatement in the Gulf of La Napoule. - Mar. Pollut. Bull. $10,163-166$.

Beyer, F., 1968. Zooplankton, zoobenthos and bottom sediments as related to pollution and water exchange in the Oslo fjord. - Helgoländer wiss. Meeresunters. 17, 496-509.

Björklund, M. I., 1974. Achievements in marine conservation. I. Marine parks. - Environ. Conserv. 1, 205-223.

Buttermore, R. E., 1977. Eutrophication of an impounded estuarine lagoon. - Mar. Pollut. Bull. 8, 13-16.

Colebrook, J. M., 1979. Continuous plankton records : monitoring the plankton of the N. Atlantic and North Sea. In: Monitoring the marine environment. Ed. by D. Nichols. Institute of Biology, London, 205 pp. (Symposia of the Institute of Biology. Nr. 24.)

Goldberg, E. (Ed.), 1973. North Sea science. MIT Press, Cambridge, Mass., 500 pp.

Gray, J. S. \& Mirza, F. B., 1979. A possible method for the detection of pollution-induced disturbance in marine benthic communities. - Mar. Pollut. Bull. 10, 142-146.

Griggs, G. B. \& Johnson, S., 1978. Bottom sediment contamination in the Bay of Naples, Italy. - Mar. Pollut. Bull. 9, 208-214.

Harrison, J. \& Grant, P., 1976. The Thames transformed. Deutsch, London, $240 \mathrm{pp}$.

I.C.E.S., 1978. On the feasibility of effects monitoring. - Coop. Res. Rep. 75, 1-42.

Johnston, R., 1977. Mechanisms and problems of marine pollution in relation to commercial fisheries. In: Marine pollution. Ed. by R. Johnston. Acad. Press, London, 3-151.

Kroger, R. L. \& Guthrie, J. F., 1971. Incidence of crooked vertebral columns in juvenile Atlantic menhaden. - Chesapeake Sci. 12, 276-278.

Lewis, J. R., 1976. Long-term ecological surveillance: practical realities in the rocky littoral. Oceanogr. mar. Biol. 14, 371-390.

Lewis, J. R., 1977. The role of physical and biological factors in the distribution and stability of rocky shore communities. In: Biology of benthic organisms. Ed. by B. F. Keegan, P. O. Ceidigh \& P. J. S. Boaden. Pergamon Press, Oxford, 417-424.

Longwell, A. C., 1977. A genetic look at fish eggs and oil. - Oceanus 20, 46-58.

McDermott, D. J. \& Sherwood, M. J., 1975. - A. Rep. Dep. Fish., Mar. Fish. Program, Coast. Water Res. Proj., El Segundo, Calif. 1974, 37.

Mearns, A. J. \& Sherwood, M. J., 1974. Environmental aspects of fin erosion and tumours in Southern California Dover Sole. - Trans. Am. Fish. Soc. 103, 299-310.

Oishi, K., Yamazaki, F. \& Harada, T., 1976. Epidermal papillomas of flat fish in the coastal waters of Hokkaido, Japan. - J. Fish. Res. Bd Can. 33, 2011-2017.

O'Sullivan, A. J., 1971. The ecological effects of sewage pollution. - Proc. R. Soc. (B) 177, 331-352.

Payne, J. F., 1976. Field evaluation of benzo(a)pyrene hydroxylase induction as a monitor for marine petroleum pollution. - Science, N. Y. 191, 945-946.

Pearson, T. H., 1975. The benthic ecology of Loch Linnhe and Loch Eil, a sea-loch system on the west coast of Scotland. IV. Changes in the benthic fauna attributable to organic enrichment. - J. exp. mar. Biol. Ecol. 20, 1-41.

Pearson, T. H. \& Rosenberg, R, 1978. Macrobenthic succession in relation to organic enrichment and pollution of the marine environment. - Oceanogr. mar. Biol. 16, 229-311.

Perkins, E. J., 1979. The effects of marine discharges on the ecology of coastal waters. In: Biological indicators of water quality. Ed. by A. James \& L. Evison. Wiley, Chichester, 1-42.

Rachor, E. \& Gerlach, S. A., 1978. Changes of macrobenthos in a sublittoral sand area of the German Bight, 1967 to 1975. - Rapp. P.-v. Réun. Cons. perm. int. Explor. Mer. 172, 418-431.

Saunders, R. L. \& Sprague, J. B., 1967. Effects of copper-zinc mining pollution on a spawning migration of Atlantic salmon. - Wat. Res. 1,419-432.

Sedgwick, R. \& Arthur, D. R., 1976. A natural pollution experiment: the effects of a sewage strike on the fauna of the Thames Estuary. - Environ. Pollut. 11, 137-160.

Southward, A. J., Butler, F. I. \& Pennycuick, L., 1975. Recent cyclic changes in climate and in abundance of marine life. - Nature, Lond. 253, 714-717.

Stich, H. F., Acton, A. B. \& Forrester, C. R., 1976. Fish tumours and sublethal effects of pollutants. - J. Fish. Res. Bd Can. 33, 1993-2001.

Tietjen, J. H., 1977. Population distribution and structure of the freeliving nematodes of Long Island Sound. - Mar. Biol. 43, 123-136. 
Waldichuk, M., 1969. Eutrophication studies in a shallow inlet on Vancouver Island. - J. Wat. Pollut. Control Fed. 41, 745-746.

Waldichuk, M., 1979. Review of the problems. - Phil. Trans. R. Soc. (B). 286, 399-422.

Wellings, S. R., Alpers, C. E., McCain, B. B. \& Miller, B. S., 1976. Fin erosion disease of starry flounder (Platichthys stellatus) and English sole (Parophrys vetulus) in the estuary of the Duwamish River, Seattle, Washington. - J. Fish. Res. Bd Can. 33, 2577-2586.

Young, J. S. \& Pearce, J. B., 1975. Shell disease in crabs and lobsters from New York Bight. - Mar. Pollut. Bull. 6, 101-105.

Young, D. R., Young, C. S. \& Hlanka, G. E., 1973. Sources of trace metals from highly urbanized southern California to the adjacent marine ecosystem. In: Cycling and control of metals. Ed. by M. G. Curry \& G. M. Gigliotti. Natural Environment Research Center, Cincinnati, Ohio, 74-81. 